\title{
YOUTH CRIME AS A 'WAY OF LIFE'? PREVALENCE AND CRIMINAL CAREER CORRELATES AMONG A SAMPLE OF JUVENILE DETAINEES in Australia
}

\author{
A PREPRINT
}

\author{
Jason L. Payne* \\ Centre for Social Research and Methods \\ Australian National University
}

\author{
Nadienne Roffey \\ Centre for Social Research and Methods \\ Australian National University
}

April 2020

\begin{abstract}
For more than 60 years, scholars have often likened chronic and persistent offending to 'living a criminal way of life', yet these evocative motifs have not received much empirical scrutiny. In particular, the socalled criminal lifestyle is often conceptualised as something the chronic young offender opts into as an alternative to other pro-social pathways. Whereas for older offenders, it is something into which they find themselves trapped an unable to escape. The idea that crime is a chosen 'way of life' among chronic young offenders has not yet received sufficient empirical scrutiny. In this study, we use archival data of nationally representative cohort $(n=373)$ of serious young offenders from Australia who were each asked whether crime was their 'way of life'. From this, we estimate its prevalence and criminal-career correlates, finding that one in three strongly identify with crime as their way of life. Self-identification is also found to be strongly correlated with Indigenous status even after controlling for different features of the juvenile criminal career. In all, our data paint a vivid portrait of a criminal identity that, for the young offender, likely signals a perceived inevitability that evolves in the context of structurally and culturally conditioned opportunities. Understanding this phenomenon among youthful offenders is important if we are to be successful in our attempts to curtail criminal continuity through desistance informed interventions.
\end{abstract}

\section{Introduction}

The frequent and persistent offender has long captured the criminological imagination. In both research and in practice, the significant yet inexplicable nature of chronic offending has inspired a multitude of creative and evocative descriptions, most of which pass us by with little or no critical analysis or empirical examination. As a consequence, we risk being ignorant to the nuances of our scholarly diction and the potential that our portrayals of young offenders may become reified into everyday criminal justice practice. Of course, the problem of reification is not new in criminology. Indeed, one of the greatest and most protracted debates ever seen in the field (Vold et al., 2010) was sparked by Alfred Blumstein and his colleagues' decision invoke the terms 'career criminal' and 'criminal career' as descriptions of prolific offenders and their longitudinal trajectories in offending (Blumstein et al., 1986a, 1986b). What followed was a decade (or two) of scholarly exchanges about the longitudinal nature of individual-level crime rates and the value of selective incapacitation in chronic offender management. These debates now serve as an important reminder that as scholars, the manner in which we describe crime ought not be accidental nor incidental and the risk of reification is real with potentially profound and long-lasting consequences.

Common among the various portrayals of persistent offending is the description of crime as a 'way of life' (Chambliss, 1967; Cohen, 1955; Shaw and McKay, 1942; Walters, 1990; West and Farrington, 1977). This particular phrase, we believe, lacks a conceptual clarity in contemporary criminology because it is seen as both the pathway of choice for serious young offenders and the object of entrapment and enslavement for older offenders, especially those looking to desist (for example, Best, 2016; Healy, 2014; Maruna, 2012; Maruna et al., 2015). It is an abstraction which intimately intersects with contemporary debates about identity, agency, criminal lifestyles (Walters, 1990; Walters, 2012) and patterns of criminal thinking (Dembo et al., 2007), yet

\footnotetext{
${ }^{*}$ Corresponding author: jason.payne@anu.edu.au
} 
the idea that crime is a 'way of life' has rarely been the subject of conceptual debate or empirical analysis. For young offenders, in particular, there is a risk that escalation and persistence in youthful offending is mis-characterised as a chosen pathway, one for which there is a need for strong deterrence or, worse, lengthy incarceration.

It is here that the present paper makes a novel and important contribution. Specifically, we draw attention to those serious young offenders who, prior to adulthood, have come to identify with crime as their way of life. We estimate the prevalence of this identification, and explore its correlates. In doing this, we analyze the conceptual intersections and ambiguities that exist in the extant literature and offer a secondary analysis of quantitative data collected from a nationally representative sample of 373 serious and high-risk young offenders in Australia. To our knowledge, this is the first study of its kind to explore the self-reported attribution of crime as a 'way of life' among young offenders in custody. In addition, our specific focus on young Australian offenders is particularly novel in that it affords a rare insight into the comparative experiences of our youngest Indigenous Australians in the criminal justice system. As the world's most highly incarcerated racial minority population who face a multiplicity of social, legal and structural barriers (Cuneen, 2007, 2008) this ought not be just an Australian curiosity, but an international priority.

\section{Crime as a 'way of life'}

It is difficult to pinpoint the first ever depiction of crime as 'way of life', though it is likely that such a phrase has long been used to describe individual and group involvement in crime through various anthropological and ethnographic lenses. In 1942, for example, Shaw and McKay made specific reference to delinquency as "an established way of life" (1942, p. 317) in a small number of urban communities in Chicago. For these scholars, crime established itself as a way of life in areas where widely accepted social and material values could not be achieved through conventional means. In this context, Shaw and McKay (1942) argued that crime can emerge as an organized way of life that proliferates in disadvantaged communities where the underprivileged seek non-conventional opportunities for accepted conventional statuses. Later, in his 1955 study, Delinquent Boys, Albert Cohen described the phenomenon of gang formation as an emerging 'way of life', one in which deviant values were institutionalized and promoted through regular contact with deviant reference groups. Unlike Shaw and McKay (1942) however, Cohen (1955) argued that the delinquent way of life was best characterized by the internalization of criminal norms and values which occurs, not through the acceptance of institutionalized norms, but through a "hostile and negativistic reaction against the dominant culture" (Cohen and Short, 1958, p. 20). Importantly, both evoke a strong sense that persistent youthful offending is a chosen way of life, although for Cohen (1955), in particular, this choice was a consequence of the purposeful pursuit of unconventional opportunities and roles, borne of a rejection of institutionalized norms.

Cohen (1955) is not alone in this portrayal of crime as a chosen way of life. In a 1967 review of deterrence research, William Chambliss described the highly committed criminal as one for whom crime had become a 'way of life', arguing that the deterrent value of different legal sanctions would likely depend on an offender's orientation towards instrumental or expressive crimes, as well as their level of criminal commitment. Specifically, Chambliss (1967, p. 712) argued that crime becomes a way of life for those who are highly committed to a pattern of social interaction and activity that revolves around opportunities for crime. He argued that these 'way of life' offenders were habitual in their offending (1967, p. 718), having strong conceptions of a criminal-self, and often perceive peer-group support for their involvement in crime. For Chambliss (1967, p. 712), the highly committed criminal is best distinguished as either instrumental (the professional thief) or expressive (the majority of drug addicts, for example), although in both cases it was the acceptance of, commitment to, and perceived social support for crime that distinguished those who engaged in crime as a 'way of life' from those who did not.

By the late 1970s, West and Farrington (1977) had reinvigorated the depiction of crime as a way of life in their book, The Delinquent Way of Life. Here, the authors explored the third wave of data from the Cambridge Study of Delinquent Development where 389 of the original 411 boys, then aged 18, had been re-interviewed. The so-called 'delinquent way of life' was not directly defined by West and Farrington (1977), although their comprehensive comparison of delinquent and non-delinquent boys portrayed a continuity of antisocial attitudes and behaviors so pervasive that delinquency might best be conceptualized as an underlying trait cutting across all domains of life. For West and Farrington, the origins of delinquency as a way of life were many and varied; although, somewhat consistent with Shaw and McKay (1942), they depicted a delinquent cohort whose behavioral trajectories were significantly conditioned by external and structural forces. Most importantly, West and Farrington's (1977) portrayed delinquency as pervasive and connected to antisocial attitudes and behaviors across multiple life domains. Accordingly, crime was simply one of a broader constellation of antisocial and delinquent outcomes and it was the propensity to delinquent behavior, in all aspects of life, which typified the 'delinquent way of life'.

While most of this literature makes implicit reference to youth crime as a chosen way of life, there is also a considerable body of work which frames youth delinquency as a normative phenomenon and persistent youth offending as a consequence of either drift, fatalism or both (Matza, 1964). David Matza, for example, describes the young delinquent as "subject to frequent oscillation between sensing himself as cause - humanism - and seeing himself as effect - fatalism" (2009, p. 88). This, Matza describes as the "mood of fatalism" (2009, p. 88); a phenomenon others have described as "the feeling of being done to instead of being done with" (Haslsey et al., 2016, p. 1044, emphasis in original). Fatalism, then, can be broadly understood as a 
self-perception or appraisal of oneself as having limited control over the unfolding of future deeds. Although Matza, himself, does not invoke the term 'way of life' his work sits as a stark but important contrast to the dominant portrayal.

\section{Crime as a lifestyle}

At about the same time as West and Farrington (1977), scholars elsewhere began to use the term 'criminal life-style' to describe the same habitual or specialized offending patterns. In a study of drugs and crime, for example, Moore (1973) describes the criminal life-style as a "significant social institution" one which "flourishes where large numbers of individuals find most paths to legitimate success blocked" (1973, p. 232). Moore's (1973) description was conceptually connected to the broader themes of work and employment, pitching the criminal life-style as more desirable than the "unskilled labor" opportunities with the "the lowest wages and no chance for advancement" (1973, p. 232). Petersilia, Greenwood and Lavin (1978) similarly described a dichotomy of criminal and non-criminal 'styles of life' (1978, p. 28) - styles between which the decision would be largely determined by the degree of motivation, instrumentality and past criminal success. It was said that the criminal style of life is most likely to be adopted when there is a strong criminal self-concept and when the offender is no longer experiencing role conflict between conventional goals and unconventional means. Finally, even Becker (1963, p. 30) placed conceptual importance on those who "sustain a pattern of deviance over a long period of time, who makes deviance a way of life [and] who organizes his identity around a pattern of deviant behavior".

In 1990, at the peak of the criminal career debates, Walters (1990) published a monograph titled, The Criminal Life-style: Patterns of Serious Criminal Conduct, in which he provides the most sophisticated and detailed account yet of crime as a way of life. He describes the criminal life-style as characterized by four main behavioral outcomes: irresponsibility in most aspects of life, self-indulgence, interpersonal intrusiveness, and norm violation that reflects an "enduring pattern" of transgression (1990, p. 71). For Walters, the 'life-style criminal' was habitual, having "constructed a belief system grounded in various early conditions and associated choices which serve to justify, support and rationalize ... subsequent behaviors" (1990, p. 16). Criminal thinking is, therefore, idiosyncratic to the criminal life-style and these thinking patterns develop "to support, buttress, and reinforce one's criminal decisions" (1990, p. 83).

In what was the first of several books detailing and refining the life-style theory of crime, Walters (1990) directly equates the criminal life-style with 'criminality as a way of life' and it is here that we see the first meaningful attempt to draw together, as synonyms, these two connected concepts (1990). A criminal life-style diagnosis, it was said, results from eight criminal thinking patterns (or thinking errors), including mollification, cutoff, entitlement, power orientation, sentimentality, super optimism, cognitive indolence, and discontinuity (Walters, 1990). Each should be identifiable in the life-style criminal, though individual offenders will differ in which of the eight thinking styles are the most influential in their offending repertoire. More recently, Walters (2016a, 2016b, 2012) has made efforts to distinguish between two types of criminal thinking styles-reactive and proactive- and argues that reactive criminal thinking patterns are more strongly tied with the 'psychological inertia' that promotes criminal continuity and persistence (Walters, 2016b). The reactive thinking style is impulsive, emotive and highly prevalent among the early onset offenders elsewhere described as having low self-control (Gottfredson and Hirschi, 1990) or long-term antisocial potential (Farrington, 2003). Although Walters does not directly equate reactive criminal thinking with life-style offending per se, it is likely that self-attribution to a criminal way of life may serve as an important signal or indicator of the social and cognitive events which characterize the psychological inertia that propels some young offenders into prolific and habitual offending as adults.

\section{'Way of life' offending as a self-attribution}

Two striking features emerge from this chronic youth offending literature. First, the bulk of the scholarship on this topic sees 'way of life' offending as a pathway chosen by young chronic offenders as either a rejection of or response to wider social pressures. This is particularly so for the early literature. In later works, this theme persists although there is a much greater effort to situate criminal decision making within a wider context of social and structural determinants. Second, is the apparent absence of any studies which seek to operationalise the 'way of life' concept as a self-attribution within youth offending populations. This is a notable omission since in the sociological and psychological literature 'lifestyles' are often conceptualised as cognitive frameworks with strong links between behaviour and self-concept. Founder of the 'Individual Psychology' perspective, Alfred Adler (1924), described 'life-style' as the unity of one's personality and self-perception. Accordingly, the style of one's life are developed early and manifest through individual efforts to achieve superiority and power, while simultaneously avoiding the uncomfortableness of a perceived inferiority. Similarly, Anthony Giddens (1991) argued that life-styles are a byproduct of modern society and that to have a life-style implies a unity of behaviors or a degree of orientation that affords a sense self and a feeling of 'ontological security' (Giddens, 1991, p. 82). For Giddens (1991) lifestyles emerge from the reflexive project of self, where behavioral choices are framed not only by a sense of how to act, but who to be in a given situation. Pierre Bourdieu (1984) refers to a similar process using the concept of 'habitus' to describe "a system of acquired dispositions, functioning on the practical level as categories of perception and assessment... as well as being the organizing principles of action" (1990, pp. 12-13). Individuals, according to Bourdieu (1990), come to experience habitus as natural within the context of the rules that 
govern what is perceived as possible and what is not in a given field or situation (described as 'doxa'). Life-styles are, therefore, contingent on habitus and the doxa through which behavioral contingencies manifest.

Although not a necessary condition, most life-style scholars imagine a direct intersection between behavior and self-concept. In doing so, they imply some self-awareness of the behavioral orientation and unity that provides the scripts for action within a life-style framework. We might imagine, then, that to self-attribute crime as a 'way of life' implies a stronger and more entrenched behavioral orientation, one that is patterned around crime and which exhibits the kind of 'commitment' earlier described by Chambliss (1967). Further, Giddens' (1991, p. 82) reference to 'ontological security' is particularly evocative in this context for it implies that those who self-attribute may derive emotional comfort and mental stability from the antisocial behavioral continuity that characterizes their offending, even if that offending is neither serious, nor habitual.

\section{Aims and objectives}

The depiction of chronic youth offending as a developing or entrenched 'way of life' requires empirical scrutiny if that depiction is inconsistent with how young people actually identify and especially if it supposes a degree of choice and agency that mischaracterises trajectories of youthful offending. A potential consequence of this is that poorly conceptualised and prejudicial views about young offenders can be reified into policy language and this can have significant and detrimental implications for criminal justice practice. In the present study, we take advantage of archival data from the Australian Institute of Criminology's (AIC) 2004 national survey of youth detainees (Prichard and Payne, 2005a) to offer the first nationally representative study of youth crime as a self-attributed 'way of life'. With these data we seek to answer three questions: (1) How many youth detainees identify with crime as a 'way of life'? (2) Are those youth who see crime as their way of life exclusively high-volume offenders? and (3) To what extent does self-attribution vary by age, race or gender?

\section{Methodology}

\section{Data and measures}

We draw on archival data from the AIC's Drug Use Careers of Offenders (DUCO) study (Johnson, 2004; Makkai and Payne, 2003; Prichard and Payne, 2005a, 2005b). Specifically, our analysis focuses on cross-sectional self-report data collected by the AIC using an interviewer-administered survey with 373 juvenile detainees (Prichard and Payne, 2005a). Conducted in 2004, the survey was an attempted census of all sentenced and un-sentenced young people residing in one of Australia's 11 juvenile detention centers. Specific and detailed findings of that original study, including a detailed methodological description, is provided elsewhere by the study's original authors (Prichard and Payne, 2005a, see), however, readers should note that final sample represents 87 percent of those who were approached for interview. Just over half (52\%) identified as Aboriginal or Torres Strait Islander and the majority $(92 \%)$ were male. Participation was voluntary and the informed consent procedures, together with the research instrument and survey protocols, were approved by the AIC's Human Research Ethics Committee (Prichard and Payne, 2005a). Access to the data for the purposes of this study has been facilitated by the Australian National University's Australian Data Archive.

The main variable of interest in the study was a single four-point ordinal item which asked each respondent to rate how much they agreed that "Committing crime is pretty much a way of life for me". The response options included: '(1) completely agree', '(2) agree quite a lot', '(3) not really agree' and '(4) don't agree at all'. We treat this variable in both its original ordinal form (four-points) as well as a dichotomous summary which differentiates those who agree completely or quite a lot (1) with those who do not or do not really agree (0).

To measure the chronicity of offending we use the respondent's self-reported frequency of prior offending. We explore two alternative measures taken from two separate sets of questions. The first is a measure of the total sum all offences the young person reported when asked "how many times in total have you ever ...". The question was asked for seven separate offence types, including vandalism, stealing/shoplifting, stealing cars, break and enter, trading in stolen goods, robbery with or without a weapon and physical assault. The second is a measure of recent offending in the six months prior to detention. For this measure, we use a question in which the respondent was asked "how often in the past six months did you..." This question was also asked for all seven offence types, although in this case a six-point response set was provided as: (a) nearly every day or every day; (b) a few times a week; (c) about once a week; (d) about monthly; (e) less than once a month; and (f) not in the last 6 months. To calculate a total frequency of recent offending we allocate a numerical multiplier to each response category which approximates the number of days (out of 180) each offence was committed. We then sum the numerical approximations across the seven offence types. We recognise that the use of self-reported offending is not ideal, although prior studies mostly agree that self-reported offending may not be sufficiently accurate as point estimates, but are robust for categorising offenders into groups of high and low-rate offenders (Payne and Piquero, 2016). For our analysis, the frequencies of prior and recent offending are both presented as a comparison of quartiles. This offers a representation of the relative ordering of offenders, rather than the absolute number of offences. We also provide estimates specific to the sub-categories of violent and property 
offending. In this study, violent offending measures the sum of an offenders self-reported assault, sexual assault and robbery offences, while property offending measures the sum of offences reported for vandalism, stealing/shoplifting, stealing cars, break and enter, trading in stolen goods.

Finally, the bivariate and multivariate analyses examine a number of key demographic, correlates. The demographic variables were: gender (coded 1 for females and 0 for males); race (coded 1 for Aboriginal or Torres Strait Islander and 0 for other); and current age at interview (coded into three groups, 11-13 years, 14-15 years and 16-17 years).

\section{Analytical approach}

The objective of the present study is relatively straightforward and so our descriptive analysis of each variable is conducted using univariate and bivariate frequency distributions together with ordinal measures of association, including gamma $(\mathrm{g})$ and Kendall's tau b as well as their associated asymptotic standard errors. For the multivariate modelling, we use logistic regression methods. For the oridinal models, in no case was the proportional odds assumption violated (confirmed using the Brant X2 test) and so we stop short of using a generalized modelling method. All analyses were undertaken using Stata v.15 (Statacorp, 2017).

\section{Results}

\section{Prevalence}

One in three (33\%) of the young offenders in this study agreed that crime was their 'way of life'. This was comprised of those who agreed 'quite a lot' (19\%) and those who agreed 'completely' (14\%) (Table 1). For the other two thirds, crime was 'not really' or 'not at all' their way of life.

\section{Correlation with chronicity and onset}

In terms of prior criminal history, there was a strong linear relationship between the self-reported frequency of prior offending and the propensity to identify with crime as a way of life. This was the case for nearly half of the highest volume offenders (49\%) but only 14 percent of the lowest rate offenders. The linear (ordinal) association seen here was statistically significant (tau $b=0.26, \mathrm{ASE}=0.04$ ). Although this trend is, overall, consistent with the literature's portrayal of youth offending as a way of life, we believe some nuance is needed here. For example, while it is true that the highest volume young offenders here are the most likely to self-attribute, still, only half of them did so. Despite being prolific offenders even by their own self-report, the other half did not agree that crime was their way of life. Similarly, while the least frequent offenders were much less likely to self-attribute their crime as a way of life, still, at least one in ten did. The key message here is that one need not be a highly prolific offender to identify with crime as a way of life. Similarly, even some of the most prolific offenders have not (at least not yet) come to identify with crime as a way of life.

The correlation between offending frequency and 'way of life' identification is not the same for both property and violent offending (Table 3). With both crime types disaggregated from Table 2, these bivariate analyses show that the frequency of both crime types are statistically significant, but that the measure of association is stronger for property offences (taub $=0.33$, $\mathrm{p}=0.00)$ that for violent offences (taub $=0.21, \mathrm{p}=0.00)$.

\section{Correlation with gender, age and race}

The number of young women is this study was small $(n=25)$, although consistent with their modest representation in the youth justice system more generally (Prichard and Payne, 2005a). On these sparse data, however, young women were less likely than young men to identify with crime as a way of life. Proportionally, fewer women completely agreed with this proposition, although the the difference here did not meet conventional levels of statistical significance $(\mathrm{g}=-0.21$, ASE=0.169).

For the 218 young Aboriginal and Torres Strait Islanders in this study, crime was identified as a way of life by 38 percent. Sixteen percent completely agreed and 21 percent agreed quite a lot. Overall, the probability of affirmative endorsement was modestly higher for these Indigenous offenders than for their non-Indigenous counterparts, a difference that was statistically significant $(\mathrm{g}=0.21, \mathrm{ASE}=0.08)$.

By age, there was a linear relationship across the age categories (tau $b=0.13$, ASE $=0.05$ ) with older offenders (16-17 years old) more likely to endorse crime as a way of life than their younger peers. That said, it is still notable that one in five of the 11-13 year olds (20\%), and one in four of the 14-15 year olds (28\%) agreed crime had become their way of life. 
A PREPRINT - APRIL 2020

Table 1: Prior criminal history and offending onset $(n=373)$

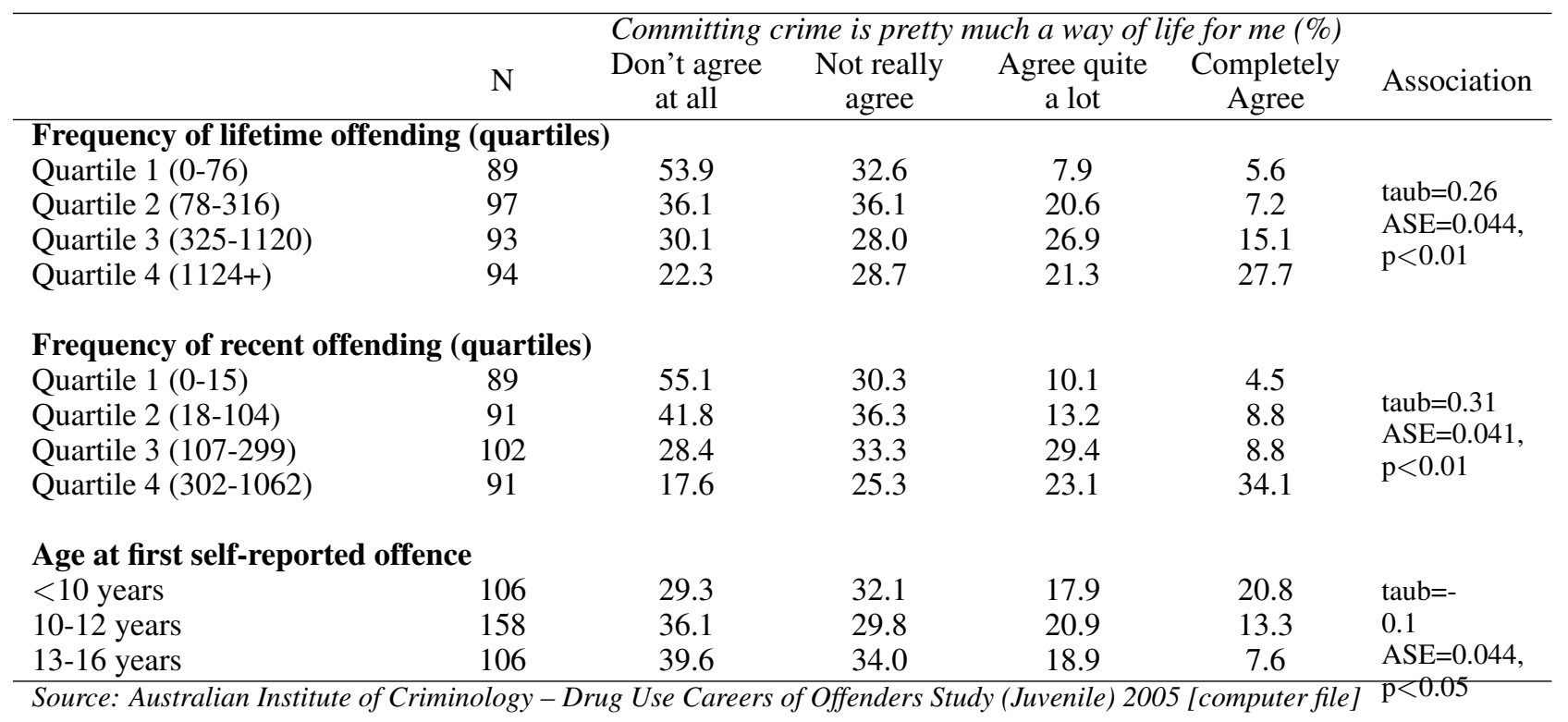

Table 2: Recent criminal history, by crime type $(n=373)$

\begin{tabular}{|c|c|c|c|c|c|c|}
\hline & \multicolumn{6}{|c|}{ Committing crime is pretty much a way of life for me (\%) } \\
\hline & $\mathrm{N}$ & $\begin{array}{c}\text { Don't agree } \\
\text { at all }\end{array}$ & $\begin{array}{l}\text { Not really } \\
\text { agree }\end{array}$ & $\begin{array}{c}\text { Agree quite } \\
\text { a lot }\end{array}$ & $\begin{array}{c}\text { Completely } \\
\text { Agree }\end{array}$ & Association \\
\hline \multicolumn{7}{|c|}{ Frequency of recent PROPERTY offending (quartiles) } \\
\hline Quartile 1 (0-9) & 86 & 55.8 & 29.1 & 9.3 & 5.8 & \multirow{4}{*}{$\begin{array}{l}\text { taub }=0.33 \\
\mathrm{ASE}=0.04 \\
\mathrm{p}<0.01\end{array}$} \\
\hline Quartile $2(12-84)$ & 91 & 40.7 & 37.4 & 15.4 & 6.6 & \\
\hline Quartile 3 (87-270) & 104 & 30.8 & 34.6 & 26.0 & 8.7 & \\
\hline Quartile $4(284+)$ & 92 & 16.3 & 23.9 & 25.0 & 34.8 & \\
\hline \multicolumn{7}{|c|}{ Frequency of recent VIOLENT offending (quartiles) } \\
\hline Quartile $1(0)$ & 125 & 46.4 & 32.0 & 10.4 & 11.2 & \multirow{4}{*}{$\begin{array}{l}\text { taub }=0.21 \\
\mathrm{ASE}=0.04 \\
\mathrm{p}<0.01\end{array}$} \\
\hline Quartile 2 (1-3) & 92 & 35.9 & 39.1 & 15.2 & 9.8 & \\
\hline Quartile 3 (6-12) & 73 & 31.5 & 27.4 & 30.1 & 11.0 & \\
\hline Quartile 4 (26-360) & 83 & 21.7 & 25.3 & 27.7 & 25.3 & \\
\hline
\end{tabular}

\section{Multivariate outcomes}

Table 4 describes the outcomes of three multivariate ordinal logistic regression models. The first examines the criminal history covariates, the second examines the demographic covariates and the third examines both. The objective of this multivariate approach is to see which of the covariates remains statistically significant once the effect of other covariates is held constant. Looking first to the model diagnostics we note that the criminal history covariates (Model 1: LL=-460.58, Pseudo R2=0.06) provide a more robust explanation of the dependent variable than the demographic covariates when modelled separately (Model 2: $L L=-480.97$, Pseudo R2=0.02). In the combined model, nested model tests show that both clusters of covariates add meaningful explanatory power (Model 2 vs. Model 3 LRX2=66.43(5), p=0.00; Model 1 vs. Model 3 LRX2=25.66(4), p=0.00).

Of the criminal history covariates, only the frequency of recent offending was statistically significant and in both Model 1 and Model 3 the results evince a clear linear trend. Notably, this trend appears to strengthen in the presence of controls for demographic variables. The age of first offence, while statistically significant in the earlier bivariate analysis, was not in either of the multivariate models. In other words, once the current frequency of offending was held constant, the propensity to identify with crime as a way of life was no longer associated with an earlier age of onset.

In terms of demographics, there remained no difference between male and female youth even after other demographic and criminal history covariates were held constant. We note, however, that the differences by gender strengthened in the combined model (Model 3), although the small sample size limits our ability to draw conclusions about gender differences at this time. 
A PREPRINT - APRIL 2020

Table 3: Gender, age and race correlates $(n=373)$

\begin{tabular}{|c|c|c|c|c|c|c|}
\hline & \multicolumn{6}{|c|}{ Committing crime is pretty much a way of life for me (\%) } \\
\hline & $\mathrm{N}$ & $\begin{array}{c}\text { Don't agree } \\
\text { at all }\end{array}$ & $\begin{array}{c}\text { Not really } \\
\text { agree }\end{array}$ & $\begin{array}{c}\text { Agree quite } \\
\text { a lot }\end{array}$ & $\begin{array}{c}\text { Completely } \\
\text { Agree }\end{array}$ & Association \\
\hline Gender & & & & & & gamma $=-$ \\
\hline Male & 348 & 34.2 & 32.5 & 19.0 & 14.4 & \\
\hline Female & 25 & 52.0 & 16.0 & 24.0 & 8.0 & $\begin{array}{l}\mathrm{ASE}=0.169 \\
\mathrm{p}=0.20\end{array}$ \\
\hline Current Age & & & & & & \\
\hline $11-13$ & 20 & 50.0 & 30.0 & 10.0 & 10.0 & $\mathrm{~b}=0.13$ \\
\hline $14-15$ & 116 & 50.0 & 27.6 & 15.5 & 0.6 & $\mathrm{ASE}=0.046$ \\
\hline $16-17$ & 237 & 30.0 & 33.3 & 21.9 & 14.8 & $\mathrm{p}<0.01$ \\
\hline Race & & & & & & gamma $=0.21$ \\
\hline Indigenous & 218 & 29.4 & 33.9 & 21.1 & 15.6 & $\mathrm{ASE}=0.079$, \\
\hline Non-Indigenous & 155 & 43.9 & 27.7 & 16.8 & 11.6 & $\mathrm{p}<0.01$ \\
\hline
\end{tabular}

Older offenders (aged 16-17 years) were the most likely to identify with crime as a way of life and this bivariate trend persisted in the multivariate models. Indeed, the difference between the youngest and the oldest offenders increased when prior criminal covariates were held constant (from $b=0.93$ to $b=1.12$ ). The same was true for race, where Indigenous youth were more likely to identify with crime as a way of life in both the bivariate and multivariate analysis and where the race differential increased in the presence of criminal history controls (from $b=0.59$ to $b=0.63$ ).

\section{Discussion}

Inspired by the criminal career and life-course persistent offender debates of the 1980s, we began this study with a reflectionthere can be no greater scholarly responsibility than to critically explore those concepts that we impart to the community of policy makers and practitioners in the criminal justice system. The reification of poorly conceptualized ideas is of genuine concern that has both ethical and practical consequences. It is in this frame that we explore what it means for a nationally representative sample of young Australian offenders to describe their crime as a 'way of life'. Such life-style descriptions have widely used in the criminological literature, finding prominence in the early cultural-criminology studies of Shaw and McKay (1942) and a more recent revival in the qualitative and ethnographic work of contemporary desistance scholars (Best, 2016; Healy, 2014; Maruna, 2012; Maruna et al., 2015). Despite its proliferation, there have been surprisingly few attempts to quantify the extent to which young offenders themselves identify with crime as a way of life. This study, albeit limited by some less-than-optimal measures from a secondary data source, is to the authors' knowledge the first large-sample $(n=373)$, nationally representative study of its kind. In particular, our access to data on young Aboriginal and Torres Strait Islander Australians-one of the worlds most incarcerated racial minority groups-makes this study an important and novel contribution to the international literature.

Of the results described above, we make a number of important observations. First, one in three serious young offenders strongly endorsed the view that crime had become their way of life. Although we made no prediction, a-priori, about the prevalence of this self-report, it seems striking that so many young offenders had already internalized their criminal trajectories into a life-course narrative. By age, there was a modestly higher endorsement rate among the oldest offenders (16-17 years), however, the association was not particularly strong and the key take-away message here is not that older offenders were more likely, but that offenders as young as 11 years can (and do) identify with crime as a way of life. This has potentially important implications for how we respond to youth crime, especially the kinds of interventions and programs we use in diversion and rehabilitation.

Second, we find a strong link between the frequency of prior offending and the propensity to identify with crime as a way of life. This correlation was strongest when measured for the most recent offending, especially the volume of recent property offending. Overall, this finding is consistent with the view that life-style attribution is more prevalent among habitual offenders, perhaps because it provides an "ontological security" (Giddens, 1991, p. 82) that reinforces a sense of self and provides an organizing and cognitive framework for rationalizing past behaviors. That said, we think the most striking finding here is that prior criminal history, though important, still only explains about six percent of the variance. In other words, there remains a number of the highest frequency offenders for whom crime was not yet seen as a way of life and, conversely, there was a number of very low frequency offenders who did. In our view, the relative weakness of this correlation suggests that life-style 
A PREPRINT - APRIL 2020

Table 4: Multivariate Ordinal Logistic Regression ( $\mathrm{n}=370)$

\begin{tabular}{|c|c|c|c|}
\hline & $\begin{array}{c}\text { Ordinal Logit Model } 1 \\
\text { Criminal History } \\
\text { b (s.e.) }\end{array}$ & $\begin{array}{c}\text { Ordinal Logit Model } 2 \\
\text { Demographics } \\
\text { b (s.e.) }\end{array}$ & $\begin{array}{c}\text { Ordinal Logit Model } 3 \\
\text { Combined } \\
\text { b (s.e.) }\end{array}$ \\
\hline \multicolumn{4}{|c|}{ Frequency of recent offending (quartiles) } \\
\hline Quartile $1(0-15)$ & (ref) & - & (ref) \\
\hline Quartile $2(18-104)$ & $0.51(0.28)^{* *}$ & - & $0.56(0.29)$ \\
\hline Quartile 3 (107-299) & $1.10(0.28)^{* *}$ & - & $1.14(0.27)^{* *}$ \\
\hline Quartile 4 (302-1062) & $2.03(0.30)^{* *}$ & - & $2.20(0.31)^{* *}$ \\
\hline \multicolumn{4}{|c|}{ Age at first self-reported offence } \\
\hline$<10$ years & (ref) & - & (ref) \\
\hline $10-12$ years & $-0.09(0.23)$ & - & $-0.10(0.24)$ \\
\hline $13-16$ years & $-0.21(0.26)$ & - & $-0.35(0.27)$ \\
\hline \multicolumn{4}{|l|}{ Gender } \\
\hline Male & - & (ref) & (ref) \\
\hline Female & - & $-0.57(0.41)$ & $-0.71(0.43)$ \\
\hline \multicolumn{4}{|l|}{ Current Age } \\
\hline $11-13$ & - & (ref) & (ref) \\
\hline $14-15$ & - & $0.45(0.46)$ & $0.39(0.48)$ \\
\hline $16-17$ & - & $0.93(0.44)^{*}$ & $1.12(0.47)^{*}$ \\
\hline \multicolumn{4}{|l|}{ Race } \\
\hline Indigenous & - & $0.59(0.20)^{* *}$ & $0.63(0.20)^{* *}$ \\
\hline Non-Indigenous & - & (ref) & (ref) \\
\hline \multicolumn{4}{|l|}{ Ordinal Thresholds } \\
\hline Threshold 1 & $0.20(0.24)$ & $-0.15(0.62)$ & $0.56(0.66)$ \\
\hline Threshold 2 & $1.67(0.26)$ & $1.21(0.62)$ & $2.11(0.67)$ \\
\hline Threshold 3 & $2.94(0.29)$ & $2.36(0.63)$ & $3.41(0.68)$ \\
\hline \multicolumn{4}{|l|}{ Model Diagnostics } \\
\hline $\mathrm{N}$ & 370 & 370 & 370 \\
\hline Loglikelihood & -460.58 & -480.97 & -447.75 \\
\hline Model X2(df) & $58.03(5)$ & $17.27(4)$ & $83.70(9)$ \\
\hline Pseudo R2 & 0.06 & 0.02 & 0.09 \\
\hline Brant X2(df) & $10.06(10)$ & $9.29(8)$ & $17.73(18)$ \\
\hline
\end{tabular}

narration is conditioned on more than just how much crime a person commits, but is intertwined into many structural, cultural and developmental processes. These require much deeper exploration in future research.

Third, the earlier a young offender onset their offending the more likely it was they they identified with crime as a way of life. This relationship held only at the bivariate level and mostly disappeared once the frequency of recent offending was controlled. We caution against interpreting this result as evidence that the age of first offence is unimportant. To be sure, early onset offending is consistently linked with higher rates of offending, so both the onset age and the frequency of recent offending are, in many respects, measuring the same thing. Similarly, the frequency of recent offending may, in fact, be an outcome of strong criminal identity, not its cause and so while it is more strongly correlated with the propensity to identify with crime as a way of life, this may be of less utility to early intervention. Put simply, since both early onset and high frequency offending are likely to be outcomes of the same aetiology (or early-life risk factors), it is not surprising that both are not needed in the same model. Nevertheless, thinking longitudinally these data suggest that early interventions should probably look to the age of onset when trying to devise strategies that minimise criminal identity internalisation amongst youthful offender populations.

Finally, perhaps the most striking of our findings was the persistent difference between young Aboriginal and Torres Strait Islanders and their non-Indigenous peers; a racial disparity that surprisingly increased in the presence of other controls. If our tentative conclusions above are correct, then this suggest that the scripting of crime into a personal and prospective life- 
style narrative occurs more often for young Indigenous Australians. This is, perhaps, because of the high frequency and intensity with which Indigenous Australians experience both structural and cultural disadvantage (Broadhurst, 1999, 2002; Cuneen, 2007, 2008; Mildren, 1997), or a response to what McCausland and Vivian (2010) describe as the 'purposelessness' of young Indigenous youth. How much the criminal life-style narrative is transmitted via cultural and intergenerational ties is not something these data can explicate. However, the higher prevalence of this phenomenon should be a cause for concern, not only because of what it might represent in terms of the insidious effects of structural and 'cultural difference' (Cuneen, 2007, p. 269), but also because of its consequences for future offending and the future growth of Australia's Indigenous incarceration rate (ABS, 2017). If, as Giddens suggested, life-style narration affords an "ontological security" in behavioral orientation (Giddens, 1991, p. 82) then the consequences of failing to acknowledge and redress these issues through culturally sensitive and decolonised programs (Kendall, 2002) will likely have significant long-term consequences.

Of course, this study is not without limitations and our conclusions above should be interpreted within this context. In particular, as a secondary analysis study, the breadth and depth of our inquiry was limited by the available data. In particular, criminal identities and criminal self-perceptions are complex phenomena that are difficult—some might say impossible- to measure quantitatively, yet many of the variables of interest in this study were single, self-reported items on a four-point scale. Critics would be justified in arguing that the DUCO study should have included multiple items whose shared covariance would represent a more complete measure, however, the DUCO study was a long and complex survey for a juvenile justice population with below average comprehension and literacy skills. Greater complexity in this context does not necessarily make for a more reliable set of data and our reliance on a single self-reported 'way of life' item, albeit limited, provides a unique window into an underexplored area. We hope that future research will provide further insights with more detailed and comprehensive measures.

There is also a risk that in our reliance on secondary data some omitted variable has biased our results. For example, we do not have procedural justice data for perceptions of the police, nor do we have information about the young offender's schooling experience or their family history of crime and incarceration. We also have reason to be cautious about the wording of specific items used in this study, as the instrument design was inconsistent in framing and tense. However, as the first large-sample study of its kind we believe that these results are an important first step in re-conceptualizing what it means for a young offender to see their crime as their way of life. Further, to execute this analysis we have assumed that the questions in this survey have cultural or social equivalence and that the disparities between Indigenous and non-Indigenous offenders represent real differences in prevalence. This assumption of equivalence is not one that can be tested in this study, however, there is evidence elsewhere that cautions against an overreliance on self-report methods, particularly for racial comparisons (Payne and Piquero, 2016, 2018). Consequently, we must be open to the possibility that the findings presented here, in particular the racial disparities, may not reflect a difference in true prevalence or propensity, but have resulted instead because of a difference in personal and culturally conditioned interpretation. In our view, this is both a limitation and a strength of this study for it reminds us that "measurement is befuddled with error' (McNemar, 1946, p. 249) and that there are genuine consequences of poor conceptualization and measurement in criminology.

\section{References}

ABS. (2017). Prisoners in australia (tech. rep.). Australian Bureau of Statistics.

Adler, A. (1924). Progress in individual psychology. British Journal of Medical Psychology, 4(1), 22-31.

Becker, H. (1963). Outsiders: Studies in the sociology of deviance. New York, NY, The Free Press.

Best, D. (2016). Social identity, social networks and social capital in desistance and recovery (A. Robinson \& P. Hamilton, Eds.). In A. Robinson \& P. Hamilton (Eds.), Moving on from crime and substance use: Transforming identities. Bristol, UK, Policy Press.

Blumstein, A., Cohen, J., Roth, J., \& Visher, C. (Eds.). (1986a). Criminal careers and "career criminals" (Vol. 1). Washington, D.C., National Academy Press.

Blumstein, A., Cohen, J., Roth, J., \& Visher, C. (1986b). Introduction: Studying criminal careers (A. Blumstein, J. Cohen, J. Roth, \& C. Visher, Eds.). In A. Blumstein, J. Cohen, J. Roth, \& C. Visher (Eds.), Criminal careers and "career criminals". Washington, D.C, National Academy Press.

Bourdieu, P. (1984). Distinction: A social critique of the judgment of taste. Cambridge, MA, Harvard University Press.

Bourdieu, P. (1990). In other words: Essays towards a reflexive sociology. Stanford, CA, Stanford University Press.

Broadhurst, R. (1999). Crime, justice and indigenous peoples: The 'new justice' and settler states. Australian and New Zealand Journal of Criminology, 32(2), 105-107.

Broadhurst, R. (2002). Crime and indigenous people (A. Graycar \& P. Grabosky, Eds.). In A. Graycar \& P. Grabosky (Eds.), The cambridge handbook of australian crimniology. Cambridge, UK, Cambridge University Press.

Chambliss, W. (1967). Types of deviance and the effectiveness of legal sanctions. Wisconsin Law Review, 1967(3), 703-719.

Cohen, A. (1955). Delinquent boys: The culture of the gang. New York, NY, The Free Press.

Cohen, A., \& Short, J. (1958). Research in delinquent subcultures. Journal of Social Issues, 14(3), 20-37. 
Cuneen, C. (2007). The criminalization of indigenous people., In Race and racialization: Essential readings. Toronto, Ontario, Canadian Scholars' Press.

Cuneen, C. (2008). Criminology, criminal justice and indigenous people: A dysfunctional relationship. Current Issues in Criminal Justice, 20, 323.

Dembo, R., Turner, C., \& Jainchill, N. (2007). An assessment of criminal thinking among incarcerated youths in three states. Criminal Justice and Behaviour, 1157-1167.

Farrington, D. P. (2003). Developmental and life-course criminology: Key theoretical and empirical issues-the 2002 sutherland award address*. Criminology, 41(2), 221-225.

Giddens, A. (1991). Modernity and self-identity: Self and society in the late modern age. Stanford, CA, Stanford University Press.

Gottfredson, M., \& Hirschi, T. (1990). A general theory of crime. Stanford, CA, Stanford University Press.

Haslsey, M., Armstrong, R., \& Wright, S. (2016). fck it!': Matza and the mood of fatalism in the desistance process. British Journal of Criminology, 1041-1060.

Healy, D. (2014). Becoming a desister: Exploring the role of agency, coping and imagination in the construction of a new self. British Journal of Criminology, 54(5), 873-891.

Johnson, H. (2004). Key findings from the drug use careers of female offenders study. Trends and Issues in Crime and Criminal Justice, (289).

Kendall, K. (2002). Time to think again about cognitive behavioural programmes. Women and punishment: The struggle for justice, 182, 98.

Makkai, T., \& Payne, J. (2003). Key findings from the drug use careers of offenders (duco) study. Trends and Issues in Crime and Criminal Justics, (267).

Maruna, S. (2012). Elements of successful desistance signaling. Criminology Public Policy, 11(1), 73-86.

Maruna, S., Coyle, B., \& Marsh, B. (2015). Desistance from crime in the transition to adulthood (B. Goldson \& J. Muncie, Eds.; Second). In B. Goldson \& J. Muncie (Eds.), Youth crime and justice (Second). London, UK, SAGE Publications.

Matza, D. (1964). Delinquency and drift. New York, Wiley.

Matza, D. (2009). Delinquency and drift. New Brunswick, New Jersey, Transaction Publishers.

McCausland, R., \& Vivian, A. (2010). Why do some aboriginal communities have lower crime rates than others? a pilot study. Australian New Zealand Journal of Criminology, 43(2), 301-332.

McNemar, Q. (1946). Opinion-attitude methodology. Psychological bulletin, 43(4), 289.

Mildren, D. (1997). Redressing the imbalance against aboriginals in the criminal justice system. Criminal Law Journal of Sydney, 21(1), 7-22.

Moore, J. (1973). Drugs and crime: A bad connection? Yale Review of Law and Social Action, 3(3).

Payne, J., \& Piquero, A. (2016). The concordance of self-reported and officially recorded lifetime offending histories: Results from a sample of australian prisoners. Journal of Criminal Justice, 46, 184-195.

Payne, J., \& Piquero, A. (2018). The concordance of self-reported and officially recorded criminal onset: Results from a sample of australian prisoners. Crime Delinquency, 64(4), 448-471.

Petersilia, J., Greenwood, P., \& Lavin, M. (1978). Criminal careers of habitual felons (tech. rep.). The Rand Corporation.

Prichard, J., \& Payne, J. (2005a). Alcohol, drugs and crime: A study of juveniles in detention (Vol. 67). Australian Institute of Criminology Canberra.

Prichard, J., \& Payne, J. (2005b). Key findings from the drug use careers of juvenile offenders study (Vol. 304). Canberra, Australian Institute of Criminology.

Shaw, C., \& McKay, H. (1942). Juvenile delinquency and urban areas. Chicago, IL, University of Chicago Press.

Statacorp. (2017). Stata.

Vold, G., Bernard, T., \& Snipes, J. (2010). Theoretical criminology. New York, NY, Oxford University Press.

Walters, G. D. (2016a). Friends, cognition, and delinquency: Proactive and reactive criminal thinking as mediators of the peer influence and peer selection effects among male delinquents. Justice Quarterly, 33(6), 1055-1079.

Walters, G. D. (2016b). Proactive and reactive criminal thinking, psychological inertia, and the crime continuity conundrum. Journal of Criminal Justice, 46, 45-51.

Walters, G. D. (1990). The criminal lifestyle: Patterns of serious criminal conduct. Newbury Park: CA, SAGE Publications.

Walters, G. D. (2012). Crime in a psychological context: From career criminals to criminal careers. Thousand Oaks, Sage.

West, D., \& Farrington, D. P. (1977). The delinquent way of life: Third report of the cambridge study in delinquent development. Oxford, OX, Heinemann Educational Books. 